\title{
Mobile games de entretenimento em práticas pedagógicas interdisciplinares
}

\author{
Larissa Salarolli Ruis - UENF - larissa.salarolli@pq.uenf.br \\ Annabell Del Real Tamariz - UENF - annabell@uenf.br \\ Silvia Cristina Freitas Batista - IFFluminense - silviac@iff.edu.br
}

\begin{abstract}
Resumo. Este artigo tem como objetivo discutir o uso pedagógico de mobile games de entretenimento em práticas interdisciplinares. Para tanto, são analisados dados obtidos por meio da literatura e de um curso de extensão promovido com licenciandos em Matemática e Geografia. Neste, duplas formadas por um licenciando de cada curso selecionaram e utilizaram mobile games de entretenimento de gestão e construção de cidades virtuais. A pesquisa teve caráter qualitativo e natureza exploratória. Foram realizadas práticas presenciais e a distância e os dados foram coletados por meio de questionário e observação. A pesquisa com os licenciandos indicou temas e conteúdos interdisciplinares a serem trabalhados a partir do uso dos mobile games testados, sinalizando a viabilidade do uso pedagógico de tais recursos.
\end{abstract}

Palavras-chave: mobile games de entretenimento, interdisciplinaridade, formação inicial de professores

\section{Pedagogical use of mobile entertainment games in interdisciplinary practices}

\begin{abstract}
This article aims to discuss the pedagogical use of mobile entertainment games in interdisciplinary practices. For this purpose, an analysis was made on data obtained not only through literature but also through an extension course promoted with undergraduate students in Mathematics and Geography who take a Teacher Degree type of course. In this experiment, pairs formed by one undergraduate of each course have selected and used mobile games of entertainment in management and construction of virtual cities. The research has qualitative character and exploratory nature. Both face to face and in distance practices were performed, the data was collected through survey questionnaire and participant observation. The research with the undergraduates pointed out interdisciplinary contents and subjects to be developed from the use of tested mobile games, signaling the viability of the pedagogical use of such resources.
\end{abstract}

Keywords: mobile entertainment games, interdisciplinarity, initial teacher training

\section{Introdução}

As tecnologias móveis têm se tornado cada vez mais ubíquas na vivência pósmoderna, convertendo-se praticamente em objetos indispensáveis no cotidiano de milhares de crianças, jovens e até mesmo adultos. Essa crescente necessidade de mobilidade e imediatismo das pessoas, a qualquer tempo e espaço, estimula a troca de informações e o compartilhamento de ideias, de experiências e de conhecimentos.

Como possibilidade emergente de uso educacional dos dispositivos móveis, têmse os mobile games. Segundo Carvalho e Ishitani (2013), essa expressão refere-se a jogos desenvolvidos para serem utilizados em smartphones, tablets e em outros dispositivos móveis. Neste contexto, de acordo com os referidos autores, encontram-se os mobile games educacionais, sendo definidos como jogos para dispositivos móveis criados com uma proposta pedagógica inserida no seu conteúdo, e os mobile games de entretenimento, definidos como os que são criados tendo o lazer como principal objetivo. Alguns estudos, como Mattar (2010) e Tori (2017), ressaltam que quando o aluno sabe que determinado jogo tem finalidade pedagógica, o encanto diminui. 
Diante disso, o uso pedagógico de jogos enfrenta o desafio de correlacionar entretenimento e educação. Considera-se que identificar possíveis temas e conteúdos a serem abordados a partir da diversão proporcionada pelos mobile games de entretenimento seja uma possibilidade para contornar essa questão. Por não contemplarem temas educacionais específicos, jogos desse tipo favorecem práticas interdisciplinares. Schimidt (2017) e Knittel et al. (2017) defendem que os mobile games de entretenimento possibilitam a interdisciplinaridade na educação pela hibridez das linguagens, pelo destaque ao pensamento autônomo, flexível, estratégico e dialógico, e pela possibilidade de jogar quando e onde quiser.

A Base Nacional Comum Curricular - BNCC (Brasil, 2018), documento de caráter normativo que define as aprendizagens essenciais que todo aluno da Educação Básica deve desenvolver, indica competências gerais que visam promover $o$ protagonismo do aluno, com apoio das novas tecnologias, e apontam para possibilidades interdisciplinares. No entanto, um dos maiores enfrentamentos na formação de futuros professores é integrar as tecnologias à educação, principalmente unindo os conhecimentos técnico-pedagógicos de forma interdisciplinar (Brasil, 2014).

Neste contexto, este artigo tem como objetivo discutir o uso pedagógico de mobile games de entretenimento em práticas interdisciplinares. A discussão tem por base o referencial teórico que fundamenta o trabalho e dados de uma pesquisa realizada com 15 licenciandos em Matemática e 15 em Geografia, de uma Instituição Federal de Educação. Para tanto, foi promovido um curso de extensão de 60 horas, com o qual se buscou contribuir para a formação dos participantes no que se refere ao uso pedagógico de mobile games e, mais especificamente, verificar possibilidades de uso interdisciplinar de mobiles games de entretenimento de gestão e construção de cidades virtuais.

No curso, foram adotadas práticas presenciais e a distância, sendo solicitada a formação de duplas com um licenciando de cada curso, que selecionaram e utilizaram mobile games de entretenimento de gestão e construção de cidades virtuais. A opção por esse tema para os mobile games considerou que este favorece a interdisciplinaridade, pois envolve aspectos econômicos, sociais, políticos, urbanos, naturais, entre outros, como defendido por Otero (2017). Além disso, estudos anteriores, promovidos pela primeira autora deste artigo, envolveram jogos digitais de construção e gestão de cidades no ensino de Geografia, o que permitiu maior familiaridade com o tema.

A pesquisa com os licenciandos foi de natureza exploratória, com abordagem qualitativa, e se configurou como uma pesquisa-formação, que como o próprio nome diz, considera sujeitos ainda em formação e não apenas professores já atuantes que visam aprimorar seu ensino (Josso, 2004). Os dados dessa pesquisa, discutidos neste artigo, foram coletados por meio de um questionário semiestruturado e observação. $\mathrm{Na}$ experiência interdisciplinar com uso dos mobile games, os participantes utilizaram seus próprios smartphones. Assim, adotou-se a perspectiva Bring Your Own Device (BYOD), que diz respeito à prática de pessoas levando seus dispositivos móveis para o local de atuação. Essa perspectiva, segundo Nichele (2015), teve origem no setor empresarial, mas tem sido cada vez mais aplicada em ações escolares.

Tendo em vista o exposto, este artigo encontra-se estruturado em quatro seções, além desta introdução. Na seção 2, discutem-se aspectos relativos ao uso de jogos digitais na educação e, em particular, ao de mobile games de entretenimento. Nas seções 3 e 4, respectivamente, descrevem-se os procedimentos metodológicos adotados e analisam-se dados coletados. Por fim, na seção 5, apresentam-se algumas considerações sobre o trabalho realizado. 


\section{Jogos Digitais na Educação e os Mobile Games de Entretenimento}

$\mathrm{Na}$ educação contemporânea, muitos professores gostariam de obter de seus alunos uma fração da atenção, motivação e produtividade que eles apresentam quando jogam seus games preferidos (Tori, 2017). No entanto, segundo esse autor, algumas abordagens educacionais contribuem para que os alunos se sintam desmotivados.

Como uma possibilidade para reverter essa situação, tem-se a aprendizagem baseada em jogos digitais, ou game based learning. De acordo com Tori (2017), os jogos digitais estabelecem rotinas, regras, ações, objetivos, feedback, conflito e interação social. Além disso, exigem tomada de decisão, resolução de problemas, aprendizagem ao lidar com o fracasso e o sucesso, bem como desenvolvem a persistência, destrezas cognitivas e motoras que os jogadores têm que aprender para serem bem-sucedidos no jogo. Para Santaella (2013), os jogos digitais oferecem, também, inúmeras possibilidades para incrementar a interdisciplinaridade.

Em contrapartida, Alves e Carvalho (2011) alertam quanto ao uso excessivo dos jogos digitais, que pode se tornar um vício para inúmeros jogadores, deixando-os dependentes. Na mesma direção, no início do ano de 2018, a Organização Mundial da Saúde (OMS), em inglês, World Health Organization (WHO), anunciou que o vício em jogos eletrônicos é caso de saúde pública em muitos países, causando transtorno mental, ou como denominado pela OMS, "transtorno do jogo" (gaming disorder) (WHO, 2018). Esse é um aspecto importante a ser considerado no uso pedagógico de jogos digitais. Além disso, $\mathrm{Wu}$ (2015) menciona que muitos docentes, por falta de conhecimentos em games, não compreendem suas possibilidades pedagógicas, principalmente quando se trata de jogos digitais de entretenimento aplicados à educação.

Para Barboza Neto e Fonseca (2013), os jogos digitais educacionais são aqueles desenvolvidos especialmente para um propósito pedagógico. Já a expressão jogos digitais na educação, segundo Tori (2017), engloba qualquer uso educacional desses jogos, incluindo os que não foram desenvolvidos para esse fim. Neste cenário, estabelecem-se dicotomias entre as duas possibilidades. Em relação aos jogos digitais educacionais, Paula e Valente (2015, p. 2) mencionam que "Em algumas situações, certas características inerentes aos jogos digitais não são respeitadas quando se tenta conceber jogos voltados especificamente à Educação, levando a um desperdício de potencial.". Assim, muitos jogos digitais educacionais não conseguem despertar a motivação intrínseca dos alunos, sendo considerados cansativos (Mattar, 2010). Por outro lado, Tori (2017) expõe que quando o aluno possui a liberdade de jogar o que, quando e com quem quiser, seu interesse nesta prática se intensifica.

Neste contexto, ao também enfatizar a liberdade de se jogar quando e onde desejar, Wolf (2017) ressalta os mobile games de entretenimento, dentre os quais alguns são comerciais e outros gratuitos. Tais games, quando adotados para fins educacionais, requerem planejamento e domínio do jogo pelo professor para mediar a construção do conhecimento, de modo a possibilitar a integração de conteúdos curriculares, de forma crítica e interativa, ao entretenimento (Wolf, 2017). São exemplos de mobile games de entretenimento: Minecraft, Angry Birds, Pokemon Go, entre outros.

No universo de uso desse tipo de mobile games em práticas interdisciplinares, algumas experiências educacionais estão sendo desenvolvidas como, por exemplo, Knittel et al. (2017), Schimidt (2017) e Araújo (2017). Knittel et al. (2017) realizaram uma experiência interdisciplinar entre Educação Física, Matemática e Ciências, com alunos dos anos finais do Ensino Fundamental I e iniciais do Ensino Fundamental II. A experiência buscou simular ecossistemas brasileiros por meio do uso do Minecraft. Os autores destacam que o professor necessita conhecer as características do jogo de entretenimento escolhido, a fim de orientar quanto aos melhores caminhos a serem 
seguidos para a realização da simulação, com qualidade, associando a virtualidade aos conteúdos a serem abordados. Outro uso interdisciplinar do Minecraft ocorreu na pesquisa de Schimidt (2017), que envolveu licenciandos em Matemática, Física e Letras, pertencentes ao Programa Institucional de Iniciação à Docência (PIBID), de modalidade interdisciplinar. A pesquisa objetivou discutir o papel dos jogos digitais na viabilização de espaços comunicativos, a partir de processos formativos envolvendo o Minecraft nas ações desenvolvidas pelo grupo interdisciplinar do PIBID. Assim como o estudo de Knittel et al. (2017), a pesquisa de Schimidt (2017) evidenciou que o papel do professor é essencial para identificar oportunidades de aprendizagem a partir das proposições implícitas no entretenimento virtual do jogo. Isso ocorre, pois "[...] os conceitos científicos não estão sistematizados, mas sim, dispersos na articulação entre o mundo da vida do estudante que realiza proposições." (Schimidt, 2017, p. 161).

A pesquisa de Araújo (2017) adotou os recursos de realidade aumentada do mobile game de entretenimento Pokemon GO. A partir da percepção interdisciplinar do pesquisador, o estudo buscou entender e descrever como professores de Geografia, Matemática e Espanhol usavam tal jogo em suas práticas pedagógicas. Assim como os estudos descritos anteriormente, a pesquisa de Araújo (2017) apontou que, como os alunos já utilizam este tipo de game para entretenimento, ao professor cabe engajá-los na realização atividades pedagógicas propostas.

Nos três estudos descritos foram utilizados smartphones dos próprios alunos. A partir de tais estudos, apresentam-se, no Quadro 1, vantagens e dificuldades do uso de mobile games de entretenimento na educação.

Quadro 1 - Vantagens e dificuldades do uso de mobile games de entretenimento na educação

\begin{tabular}{|c|c|c|}
\hline Trabalhos & Vantagens & Dificuldades \\
\hline $\begin{array}{l}\text { Araújo } \\
\text { (2017) }\end{array}$ & $\begin{array}{l}\text { Interação entre os alunos e as atividades } \\
\text { pedagógicas; motivação da } \\
\text { aprendizagem; autonomia; criatividade; } \\
\text { diversão; resolução de problemas. }\end{array}$ & $\begin{array}{l}\text { Desinteresse e/ou falta de preparo docente } \\
\text { para trabalhar com jogos digitais de } \\
\text { entretenimento na educação. }\end{array}$ \\
\hline $\begin{array}{l}\text { Knittel et } \\
\text { al. (2017) }\end{array}$ & $\begin{array}{l}\text { Resolução de situações-problema; } \\
\text { colaboração; criatividade; estímulo à } \\
\text { aprendizagem ativa; cooperação; } \\
\text { aproximação de conhecimentos teóricos; } \\
\text { reprodução da realidade em um ambiente } \\
\text { virtual. }\end{array}$ & $\begin{array}{l}\text { Dificuldade em trabalhar com blocos na } \\
\text { conversão de medidas no ambiente virtual; } \\
\text { reduzido conhecimento técnico-pedagógico } \\
\text { dos professores. }\end{array}$ \\
\hline $\begin{array}{l}\text { Schimidt } \\
(2017)\end{array}$ & $\begin{array}{l}\text { Ação colaborativa; ação-reflexão; } \\
\text { problematização da realidade; } \\
\text { possibilidade de levantamento de } \\
\text { proposições dos estudantes sobre a } \\
\text { temática estudada em relação ao jogo; } \\
\text { desenvolvimento simultâneo da } \\
\text { consciência crítica e lógica. }\end{array}$ & $\begin{array}{l}\text { Conceitos científicos não sistematizados; } \\
\text { necessidade de profundo conhecimento } \\
\text { docente na detecção e sistematização de } \\
\text { conceitos disciplinares e r temas } \\
\text { interdisciplinares; necessidade r de } \\
\text { compreensão crítica e emancipatória dos } \\
\text { processos formativos; instabilidade de } \\
\text { conexão à internet na escola. }\end{array}$ \\
\hline
\end{tabular}

Fonte: Elaboração própria, a partir dos trabalhos citados.

Finalizando essa seção, destacam-se algumas reflexões gerais sobre o uso pedagógico de mobile games de entretenimento em situações de interdisciplinaridade: i) importância de se discutir, durante o processo de formação docente, a utilização crítica desses games, tendo em vista propostas pedagógicas interdisciplinares; ii) necessidade de se considerar a realidade dos alunos; iii) possibilidade de criar espaços educacionais híbridos, prolongando as atividades propostas e minimizando os problemas com a infraestrutura; iv) necessidade de planejar, testar e avaliar previamente os games, a fim de antecipar possíveis problemas e associar os acontecimentos do jogo aos conteúdos propostos; v) propiciar a reflexão dialógica do entretenimento em relação às possibilidades educacionais inseridas de forma indireta nos mobile games. 


\section{Material e Métodos}

A partir da fundamentação teórica realizada, foi idealizado um conjunto de práticas formativas híbridas (presenciais e a distância), a serem desenvolvidas de forma interdisciplinar com licenciandos em Matemática e Geografia. A pesquisa, de natureza exploratória e caráter qualitativo, configurou-se como pesquisa-formação. Segundo Josso (2004), este tipo de pesquisa é definido como sendo uma metodologia que contempla a possibilidade de mudança de práticas, bem como dos sujeitos em formação. Assim, a pessoa é ao mesmo tempo objeto e sujeito da formação (Josso, 2004).

Para a experimentação das práticas formativas delineadas, foi organizado um curso de extensão, promovido pelo Programa de Pós-Graduação em Cognição e Linguagem de uma Universidade Estadual do interior do estado do Rio de Janeiro, no período de julho a setembro de 2018. O curso foi intitulado "Interdisciplinaridade, Ensino e Tecnologia por meio de Mobile Games de Entretenimento" e teve a participação de 15 licenciandos em Matemática e 15 em Geografia de uma Instituição Federal de Educação.

Esses 30 licenciandos foram divididos em duplas interdisciplinares para a execução das atividades. Os participantes tinham como missão vislumbrar possíveis temas e conteúdos a serem trabalhados de modo interdisciplinar entre Geografia e Matemática, a partir do uso de um mobile game de entretenimento de gestão e construção de cidades virtuais. A escolha desse tema para os mobile games levou em consideração dois aspectos: a possibilidade de trabalhar, de forma holística, aspectos econômicos, sociais, políticos, urbanos, naturais, entre outros, como defendido por Otero (2017), e a familiaridade da primeira autora deste artigo com o assunto, decorrente de pesquisa anterior (Ruis; Zacchi, 2018) envolvendo jogos digitais de construção e gestão de cidades no ensino de Geografia.

Para fornecer uma visão geral do curso de extensão, apresenta-se no Quadro 2 um resumo das atividades propostas.

Quadro 2- Atividades do curso de extensão

\begin{tabular}{|c|c|c|}
\hline \multirow[b]{2}{*}{$\begin{array}{l}\text { ETAPA 1: } \\
\text { Inscrições }\end{array}$} & Processo de inscrição & $\begin{array}{l}\text { Divulgação do curso de capacitação e inscrição por meio de } \\
\text { um formulário digital. }\end{array}$ \\
\hline & $\begin{array}{l}\text { Processo de seleção de } \\
\text { participantes a partir } \\
\text { dos requisitos exigidos } \\
\text { para a prática do curso }\end{array}$ & $\begin{array}{l}\text { Requisitos mínimos para a seleção: i) ser licenciando em } \\
\text { Geografia ou em Matemática, a partir do } 2^{\circ} \text { período; ii) } \\
\text { possuir um dispositivo móvel com acesso à internet e, no } \\
\text { mínimo } 200 \text { MB de memória de armazenamento disponível; } \\
\text { iii) ter disponibilidade de tempo para execução das etapas do } \\
\text { curso. }\end{array}$ \\
\hline \multirow{2}{*}{$\begin{array}{l}\text { ETAPA 2: } \\
\text { Práticas } \\
\text { Presenciais }\end{array}$} & \multirow{2}{*}{$\begin{array}{c}\text { Mobile Games sob a } \\
\text { perspectiva BYOD: } \\
\text { construindo cidades na } \\
\text { tela do seu dispositivo } \\
\text { móvel }\end{array}$} & $\begin{array}{l}\text { Discussão teórica: i) ensino híbrido; ii) estratégias BYOD; } \\
\text { iii) interdisciplinaridade da cidade; iv) jogos na educação, } \\
\text { com ênfase nos mobile games de entretenimento. }\end{array}$ \\
\hline & & $\begin{array}{l}\text { Pesquisa, teste e seleção de mobile games de entretenimento } \\
\text { de gestão e construção de cidades virtuais. }\end{array}$ \\
\hline \multirow{3}{*}{$\begin{array}{l}\text { ETAPA 3: } \\
\text { Práticas a } \\
\text { Distância }\end{array}$} & Jogabilidade & $\begin{array}{l}\text { Prática individual dos licenciandos em jogar o mobile game } \\
\text { escolhido pela dupla. }\end{array}$ \\
\hline & $\begin{array}{l}\text { Interação nas redes } \\
\text { sociais digitais }\end{array}$ & $\begin{array}{l}\text { Interação nos grupos do Facebook e do WhatsApp, a fim de } \\
\text { trocar informações e materiais referentes aos mobile games. }\end{array}$ \\
\hline & $\begin{array}{l}\text { Registro em diário } \\
\text { virtual de campo }\end{array}$ & $\begin{array}{l}\text { Criação de um diário virtual de campo por meio do Google } \\
\text { Sites, para registro das práticas pedagógicas } \\
\text { interdisciplinares identificadas pelas duplas a partir do uso } \\
\text { do mobile game escolhido. }\end{array}$ \\
\hline
\end{tabular}

Fonte: Elaboração própria.

$\mathrm{Na}$ etapa presencial do curso, foram realizados três encontros no Instituto Federal no qual os participantes estudavam. No terceiro encontro, os licenciandos de cada dupla pesquisaram e selecionaram um mobile game do tipo especificado, utilizando seus 
próprios smartphones, de forma condizente com a perspectiva BYOD. Para essa seleção, foram estabelecidos os seguintes critérios: i) ser um jogo de entretenimento com foco na gestão e construção de cidades virtuais; ii) ser gratuito; iii) ter potencial interdisciplinar, contemplando principalmente áreas relacionadas à Geografia e à Matemática; iv) possuir compatibilidade com os sistemas operacionais dos dispositivos móveis de todos os participantes do curso, ou seja, Android e iOS. Para tanto, realizouse a busca nas respectivas lojas virtuais dos sistemas operacionais citados, porém, os licenciandos foram orientados a selecionarem apenas jogos disponíveis nas lojas virtuais dos dois sistemas operacionais.

As práticas presenciais associaram a teoria à prática, conforme Quadro 2. $\mathrm{Na}$ etapa a distância, os participantes tinham que registrar por meio de um diário virtual de campo - criado pela dupla no Google Sites - as práticas interdisciplinares entre Geografia e Matemática idealizadas, envolvendo a temática cidade.

Os dados referentes à percepção dos licenciandos sobre a experiência com os mobile games de entretenimento em práticas pedagógicas interdisciplinares, discutidos neste artigo, foram coletados por meio de um questionário semiestruturado $\mathrm{e}$ observação. Ressalta-se que a coleta e a divulgação dos resultados da pesquisa foram autorizadas pelos participantes, em termo específico para tal fim.

Todos os 30 licenciandos concluíram o curso e para a análise de dados, promovida na seção seguinte, as 15 duplas foram nomeadas D1, D2, D3, ..., D15.

\section{Resultados e Discussão}

\subsection{Experiência Interdisciplinar: identificação de temas e conteúdos}

No início da pesquisa, os licenciandos foram orientados sobre as atividades do curso, incluindo a necessidade de escolha de um mobile game de entretenimento de gestão e construção de cidades virtuais, de acordo com os critérios estabelecidos. Conforme foram testando os mobile games, os licenciandos elencaram os que se adequavam à proposta. $\mathrm{O}$ Quadro 3 apresenta os mobile games selecionados pelas duplas, assim como uma breve descrição de cada jogo.

Quadro 3 - mobile games escolhidos

\begin{tabular}{|c|c|l|}
\hline Dupla & Mobile game & \multicolumn{1}{|c|}{ Descrição sumária do mobile game } \\
\hline $\begin{array}{c}\text { D2; D11; } \\
\text { D12; D15 }\end{array}$ & Little Big City 2 & $\begin{array}{l}\text { O jogo tem como cenário uma ilha remota, onde o jogador precisa } \\
\text { cuidar de todas as necessidades da população e atrair novos } \\
\text { moradores para a região. }\end{array}$ \\
\hline $\begin{array}{c}\text { D1; D3; } \\
\text { D6; D7 }\end{array}$ & Megapolis & $\begin{array}{l}\text { O jogo desenvolve-se por meio de uma série de missões. Oferece centenas } \\
\text { de opções comerciais, industriais e residenciais, que auxiliam na captação } \\
\text { de créditos e recursos. }\end{array}$ \\
\hline $\begin{array}{c}\text { D4; D9; } \\
\text { D13 }\end{array}$ & SimCity Buildit & $\begin{array}{l}\text { O jogo começa com apenas uma rua e cabe ao jogador construir } \\
\text { novas casas, indústrias, áreas comerciais e toda infraestrutura para dar } \\
\text { suporte aos moradores e desenvolver a sua cidade. }\end{array}$ \\
\hline D5; D8 & 2020: Meu País & $\begin{array}{l}\text { O jogador constrói e governa uma metrópole futurista, em uma série } \\
\text { de cidades insulares. }\end{array}$ \\
\hline D10 & City Mania & $\begin{array}{l}\text { Além da gestão e construção da cidade virtual, o jogo permite criar } \\
\text { personagens casuais e desenvolver a interação social dos avatares. }\end{array}$ \\
\hline D14 & $\begin{array}{l}\text { Jogo de criação de cidades futuristas, tendo como cenário o espaço. O } \\
\text { jogador deve criar e gerir uma civilização sustentável num planeta } \\
\text { desolado. }\end{array}$ \\
\hline
\end{tabular}

Fonte: Elaboração própria.

$\mathrm{Na}$ etapa a distância, os participantes tiveram como missão vislumbrar possíveis temas e conteúdos a serem trabalhados de modo interdisciplinar entre Geografia e Matemática, a partir do uso do mobile game selecionado pela dupla, além de registrar tais possibilidades no diário virtual de campo da dupla. O Quadro 4, apresenta os temas e conteúdos vislumbrados. 
Quadro 4 - Temas e conteúdos vislumbrados

\begin{tabular}{|c|c|c|}
\hline $\begin{array}{l}\text { Dupla/Mobile } \\
\text { Game }\end{array}$ & Tema & Conteúdos a serem trabalhados de modo interdisciplinar \\
\hline D1 - Megapolis & Meio ambiente & $\begin{array}{l}\text { Espaço e forma; área e proporcionalidade direta; formas } \\
\text { geométricas; preservação e meio ambiente. }\end{array}$ \\
\hline \multirow{3}{*}{$\begin{array}{l}\text { D2 - Little Big } \\
\quad \text { City } 2\end{array}$} & Economia & $\begin{array}{l}\text { Conceitos geográficos de cidade (cidades pequenas, médias, } \\
\text { metrópoles); Funções: comparação do número de habitantes } \\
\text { e arrecadação de impostos do município. }\end{array}$ \\
\hline & $\begin{array}{l}\text { Aproveitamento do } \\
\text { solo urbano }\end{array}$ & $\begin{array}{l}\text { Conceito de Centro x Periferia; Planejamento urbano; } \\
\text { Operações matemáticas para cálculo da área de abrangências } \\
\text { de serviços públicos, buscando otimizar o uso do solo } \\
\text { urbano. }\end{array}$ \\
\hline & População & $\begin{array}{l}\text { Densidade demográfica; Razão; } \\
\text { Operações matemáticas. }\end{array}$ \\
\hline D3 - Megapolis & $\begin{array}{l}\text { Recursos renováveis: } \\
\text { impactos geográficos, } \\
\text { populacionais e de } \\
\text { custo benefício }\end{array}$ & $\begin{array}{l}\text { Crescimento populacional; Produção de energia solar, eólica } \\
\text { e hídrica; Construção de usinas nucleares e hidrelétricas; } \\
\text { Custos financeiros, limitações e possibilidades de cada tipo } \\
\text { de energia. }\end{array}$ \\
\hline $\begin{array}{l}\text { D4 - SimCity } \\
\text { Buildit }\end{array}$ & Não identificado & Urbanização; Serviços básicos e Recursos financeiros. \\
\hline $\begin{array}{l}\text { D5 - 2020: } \mathrm{Meu} \\
\text { País }\end{array}$ & Não identificado & $\begin{array}{l}\text { Geografia urbana; Cartografia; Sustentabilidade; Economia; } \\
\text { Geometria; Conversão de medidas para realização de } \\
\text { cálculos de transformação de energia; Raciocínio lógico; } \\
\text { Estatística para calcular investimentos. }\end{array}$ \\
\hline D6 -Megapolis & $\begin{array}{l}\text { Desenvolvimento } \\
\text { urbano }\end{array}$ & $\begin{array}{l}\text { Noções de espaço; Operações matemáticas; Economia; } \\
\text { Medidas; Urbanização. }\end{array}$ \\
\hline D7 - Megapolis & Sustentabilidade & $\begin{array}{l}\text { Fontes energéticas; Poluição; Densidade demográfica; } \\
\text { Noções de área e perímetro; Impactos ambientais e } \\
\text { econômicos. }\end{array}$ \\
\hline $\begin{array}{l}\mathrm{D} 8 \text { - 2020: } \mathrm{Meu} \\
\text { país }\end{array}$ & Não identificado & Administração financeira e territorial. \\
\hline $\begin{array}{l}\text { D9 - SimCity } \\
\text { Buildit }\end{array}$ & Meio ambiente & $\begin{array}{l}\text { Sustentabilidade; Urbanização; Áreas de figuras planas; } \\
\text { Equivalência entre áreas; Industrialização; Poluição. }\end{array}$ \\
\hline $\begin{array}{l}\text { D10 - City } \\
\text { Mania }\end{array}$ & Não identificado & $\begin{array}{l}\text { Área; Poluição Urbana; Planejamento Urbano; Políticas } \\
\text { Públicas; Gestão financeira. }\end{array}$ \\
\hline $\begin{array}{l}\text { D11 - Little Big } \\
\text { City } 2\end{array}$ & $\begin{array}{c}\text { Densidade } \\
\text { demográfica }\end{array}$ & Demografia; Geometria; Aritmética; Espaço geográfico. \\
\hline \multirow{2}{*}{$\begin{array}{l}\text { D12 - Little Big } \\
\text { City } 2\end{array}$} & Demografia & Área; Razão; Proporção; Densidade Demográfica. \\
\hline & Industrialização & $\begin{array}{l}\text { Industrialização; Urbanização; Porcentagem; Impactos } \\
\text { ecológicos. }\end{array}$ \\
\hline $\begin{array}{l}\text { D13 - SimCity } \\
\quad \text { Buildit }\end{array}$ & Preço e Território & $\begin{array}{l}\text { Espaço e território; Área; Crescimento populacional; } \\
\text { Industrialização; Arrecadação de impostos; Operações } \\
\text { matemáticas; Desenvolvimento urbano. }\end{array}$ \\
\hline $\begin{array}{l}\text { D14 - Space } \\
\quad \text { City }\end{array}$ & $\begin{array}{l}\text { Progresso e } \\
\text { Problemas } \\
\text { Ambientais } \\
\end{array}$ & $\begin{array}{l}\text { Gestão do espaço; Espaço urbano; Área; Produção do } \\
\text { espaço capitalista. }\end{array}$ \\
\hline $\begin{array}{l}\text { D15 - Little Big } \\
\quad \text { City } 2\end{array}$ & $\begin{array}{l}\text { Desmatamento e } \\
\text { densidade } \\
\text { demográfica }\end{array}$ & $\begin{array}{l}\text { Sustentabilidade; Impactos ambientais; Crescimento } \\
\text { populacional; Análise de mapas e gráficos; Área; Medidas; } \\
\text { Porcentagem. }\end{array}$ \\
\hline
\end{tabular}

Fonte: Elaboração própria.

Ressalta-se que nos diários virtuais de campo das duplas D4, D5, D8 e D10 não foram identificados os temas vislumbrados. As referidas duplas citaram apenas os possíveis conteúdos a serem trabalhos de modo interdisciplinar. A partir da análise dos dados do Quadro 4, foi possível identificar dois macro temas interdisciplinares: meio ambiente e densidade demográfica. Considerando cada disciplina, destacam-se os principais conteúdos identificados na virtualidade dos jogos: i) Geografia: 
sustentabilidade, demografia, políticas públicas, planejamento urbano, espaço, território, entre outros; ii) Matemática: geometria plana, sistema financeiro, economia, operações matemáticas, razão, proporção, funções, entre outros. Como sugestão de metodologia pedagógica subjacente à aplicação de cada jogo, indica-se que os temas e conteúdos destacados sejam explorados por meio da aprendizagem baseada em jogos digitais (Prensky, 2012). Além disso, considera-se que por meio dos mobile games analisados é possível promover práticas pedagógicas interdisciplinares entre Geografia e Matemática, embora, seja plausível ponderar que alguns desses games apresentam propostas mais favoráveis a isso do que outros.

\subsection{Percepção dos licenciandos sobre a experiência vivenciada}

Os dados obtidos por meio do questionário permitiram identificar se os participantes conseguiram vislumbrar muitas ou poucas possibilidades interdisciplinares entre Geografia e Matemática, a partir do uso dos mobile games considerados: i) muitas possibilidades interdisciplinares: $46,4 \%$ dos licenciandos; ii) possibilidades intermediárias: $35,7 \%$ dos licenciandos; iii) poucas possibilidades: $17,8 \%$ dos licenciandos. A percepção de poucas ou intermediárias possibilidades interdisciplinares é coerente com a visão de $\mathrm{Wu}$ (2015), quando este afirma que muitos docentes, por não terem conhecimentos aprofundados em jogos digitais, não compreendem suas possibilidades disciplinares e interdisciplinares.

Observou-se, também, a partir da interação dos licenciandos por meio das redes sociais digitais WhatsApp e Facebook, concebidas no curso como comunidades de compartilhamento de ideias, que, em alguns momentos, uma área do conhecimento era mais beneficiada do que a outra. Porém, de forma geral, foi possível identificar propostas interdisciplinares entre as duas áreas. Ressalta-se que em diversos momentos os licenciandos também destacaram a possibilidade de inserir a Biologia nas propostas interdisciplinares. De modo geral, os licenciandos destacaram que a aprendizagem baseada em jogos digitais, metodologia subjacente à pesquisa realizada, contribuiu para aprender por meio de erros, tentativas e descobertas e em colaboração com os colegas.

A respeito da contribuição da integração das redes sociais digitais para facilitar a jogabilidade e compartilhamento de ideias e dificuldades, na etapa a distância, 93,3\% dos participantes responderam afirmativamente. Os outros 6,7\% responderam que essa integração não contribuiu, mas justificaram pela falta de dificuldade com os mobile games, o que foi positivo também. Percebeu-se que mesmo sendo jogos diferentes, porém com narrativas semelhantes, a interação motivou os licenciandos, evitando possíveis situações de conflito no jogo.

Em relação à estratégia BYOD, adotada no curso, 39,4\% consideraram uma ótima estratégia, $35,7 \%$ boa, $10,7 \%$ regular e 14,2\% consideraram ruim. Apesar de reconhecerem os benefícios do uso do próprio dispositivo, alguns licenciandos entendem que em algumas situações não será possível sua aplicação, devido às condições socioeconômicas dos alunos, bem como à diversidade de configurações dos dispositivos dos alunos e ao acesso precário à internet. Nichele (2015) afirma que a instituição de ensino deverá assegurar uma infraestrutura adequada, principalmente referente ao acesso à banda larga de qualidade, a fim de suportar as possibilidades metodológicas que envolvam a aprendizagem com mobilidade. A possibilidade de estimular os estudantes a explorarem e (re)descobrirem o potencial de seus próprios dispositivos móveis em situações de entretenimento, incrementados ao contexto educacional, é um elemento chave para a adoção da estratégia BYOD (Nichele, 2015).

Por fim, a avaliação dos licenciandos sobre o curso de extensão indicou que para $82,1 \%$ dos licenciandos foi uma ótima experiência, para 7,2\% foi boa, para 3,6\% foi regular e $7,1 \%$ considerou a experiência ruim. Em seus relatos, os licenciandos que 
assinalaram a opção regular ou ruim alegaram ter sido penoso o registro nos diários virtuais de campo. Ressalta-se que tal registro ocorreu em um período de término do semestre letivo dos licenciandos, que possuíam outras atividades para realizar. Além disso, a partir dos relatos, observou-se que a prática de registros dessa forma não era usual entre os participantes. Segundo Nichele (2015), na formação inicial de professores é de suma importância descrever e refletir sobre os próprios posicionamentos pedagógicos, sobre possibilidades de ensino e sobre propostas diferenciadas, para que os licenciandos possam aprimorar sua futura prática profissional.

\section{Considerações Finais}

A experiência interdisciplinar promovida ressaltou o uso de mobile games de entretenimento, tendo como foco a construção e gestão de cidades virtuais, como possibilidade pedagógica interdisciplinar entre Geografia e Matemática. Verificou-se que os mobile games de entretenimento desta natureza, aliados à perspectiva BYOD, podem ser importantes instrumentos didáticos. Porém, o professor deverá analisar de forma cautelosa as variáveis positivas e negativas que esses recursos podem trazer à tona, sem perder o foco nos conteúdos a serem trabalhados. Ressalta-se que não foi objetivo do estudo indicar o melhor mobile game de entretenimento de gestão e construção de cidades virtuais a ser usado como recurso interdisciplinar, mas sim apresentar diferentes perspectivas e possibilidades identificadas por futuros professores de Geografia e Matemática, por meio da virtualidade dos mobile games selecionados.

A pesquisa revelou que podem existir muitas conexões entre Geografia e Matemática, sendo algumas mais perceptíveis em determinados mobile games do que em outros, além de ser possível a introdução de outras disciplinas que dialoguem com o tema gerador adotado por esta pesquisa.

Observou-se, ainda, que é imprescindível que as práticas pedagógicas que prevejam a adoção de mobile games nos dispositivos dos próprios alunos sejam concebidas para serem desenvolvidas em mais de um sistema operacional, ou seja, multiplataforma, considerando a realidade dos alunos, de modo a não excluir alguns. Além disso, é necessário criar espaços educacionais híbridos, prolongando as atividades propostas e minimizando os problemas com a infraestrutura das instituições de ensino. Desta forma, a interação por meio das redes sociais digitais e registros sucintos em diários virtuais de campo podem ser grandes aliados em atividades híbridas, a partir da adoção metodológica da aprendizagem baseada em jogos digitais.

A principal dificuldade encontrada pela pesquisadora-formadora, ao ministrar o curso, foi conduzir o processo interdisciplinar, não favorecendo mais uma área do conhecimento do que outra. Além disso, realizar a mediação entre os licenciandos, a fim de que enxergassem possibilidades críticas e não apenas capitalistas implícitas aos mobile games de entretenimento de gestão e construção de cidades virtuais, foi um grande desafio. Como forma de continuidade do estudo, é possível analisar a contribuição interdisciplinar em outras disciplinas, deixando em aberto a escolha do tipo de mobile games de entretenimento, não se restringindo aos jogos de gestão e construção de cidades virtuais.

\section{REFERÊNCIAS}

ALVES, L.; CARVALHO, A. Videogame: é do bem ou do mal? Como orientar os pais. Revista Psicologia em Estudo, v. 16, n. 2, p. 251-258. 2011.

ARAÚJO, S. de. Práticas docentes para otimizar a aprendizagem através do uso do fenômeno relâmpago Pokemon GO. Em Pauta - Revista Eletrônica dos Cursos de Engenharia do Centro Universitário UniOpet, Curitiba - PR, v.1 n.1, p. 14 - 30, 2017. 
BARBOSA NETO, J. F.; FONSECA, F. S. Jogos educativos em dispositivos móveis como auxílio ao ensino da matemática. Revista Novas Tecnologias na Educação (RENOTE), v.11, n.1, 2013.

BRASIL. Ministério da Educação. Base Nacional Curricular Comum: educação é a base. Secretaria de Educação Básica. Brasília, MEC/CONSED/UNDIME, 2018.

Disponível em: $<$ http://basenacionalcomum.mec.gov.br/images/BNCC_20dez_site.pdf $>$ Acesso em: 03 jan. 2018.

BRASIL. Novas tecnologias facilitam a aprendizagem escolar. 2014. Disponível em: $<$ http://www.brasil.gov.br/educacao/2014/07/novas-tecnologias-facilitamaprendizagemescolar>. Acesso em: 20 jan. 2018.

CARVALHO, R. N. S. d.; ISHITANI, L. Fatores motivacionais para desenvolvimento de mobile serious games com foco no público da terceira idade: uma revisão de literatura. Educação Temática Digital, v.15, n.1, p 16-32, 2013.

JOSSO, M. C. Experiências de vida e formação. Trad. José Claudino e Júlia Ferreira. São Paulo: Cortez, 2004.

KNITTEL, T.; SANTANA, L.; PEREIRA, M.; MENUZZI, M. Minecraft: experiências de uso dentro e fora da sala de aula. In: SIMPÓSIO BRASILEIRO DE JOGOS E ENTRETENIMENTO DIGITAL, 16., 2017. Curitiba. Anais. Curitiba: Pontifícia Universidade Católica do Paraná, 2017, p. 789 - 795.

MATTAR, J. Games em educação: como os nativos digitais aprendem. São Paulo: Pearson Prentice Hall, 2010.

NICHELE, A. G. Tecnologias Móveis e Sem Fio nos Processos de Ensino e Aprendizagem em Química: uma experiência no Instituto Federal de Educação Ciência e Tecnologia do Rio Grande do Sul. Porto Alegre: UNISINOS, 2015. $258 f$. Tese de Doutorado.

OTERO. E. A interdisciplinaridade da (e na) cidade. Revista Organizações e Sociedade, v.6, n.6, p.1-4, 2017.

PAULA, B. H.; VALENTE, J. A. Errando para aprender: a importância dos desafios e dos fracassos para os jogos digitais na Educação. Revista Novas Tecnologias na Educação (RENOTE), v.13, n.2, 2015.

PRENSKY, M. Aprendizagem baseada em jogos digitais. São Paulo: Editora Senac São Paulo, 2012.

RUIS, L. S.; ZACCHI, R. C. Jogos na Educação: a simulação de cidades virtuais como ferramenta didática para o ensino de Geografia. In: GOBBO, A. (Org.). A educação em tempos da revolução das máquinas. São Paulo: Pimenta Cultural, 2018, p. 111 - 130. SCHIMIDT, D. A. T. Espaços Comunicativos e Jogos Digitais: processos formativos com a inserção do jogo Minecraft no contexto do ensino superior e da educação básica. Curitiba: UFPR, 2017. 179f. Dissertação de Mestrado.

TORI, R. Educação sem Distância: as tecnologias interativas na redução de distâncias em ensino e aprendizagem. 2. ed. São Paulo: Artesanato Educacional, 2017.

WHO. Gaming disorder. 2018. Disponível em: $<$ http://www.who.int/features/qa/gamingdisorder/en/>. Acesso em: 20 jan. 2018. WOLF, M. Video games as american popular culture. Em Pauta - Quaderns da Concordia University of Wisconsin, Mequon, n.12, p. 119-128, 2017.

WU, M. L. Teachers experience, attitudes, self-efficacy and perceived barriers to the use of digital game-based learning: A survey study through thelens of a typology of educational digital games. Michigan: MSU, 2015. 152f. Tese de Doutorado. 